\title{
CS Research Square

\section{Factors Influencing the Utilization of Community Cultural and Leisure Services for the Older Adults From The Perspective of Supply and Demand: Based on the Case of Shaanxi Province}

Qing Niu

Xi'an Jiaotong University

Chi Zhang

Xi'an Jiaotong University

Zhao Yu ( $\nabla$ yuzhao@stu.xjtu.edu.cn )

Xi'an Jiaotong University

Sifeng Zhang

Xi'an Jiaotong University

\section{Research Article}

Keywords: community cultural and leisure services, service utilization, supply-side factors, demand-side factors, older adults

Posted Date: April 21st, 2021

DOI: https://doi.org/10.21203/rs.3.rs-405412/v1

License: (c) (i) This work is licensed under a Creative Commons Attribution 4.0 International License.

Read Full License 


\section{Abstract \\ Background}

Along with the increasing number of older adults in China, the demand for older adults services of China's aging population has been transformed and upgraded, and the demand for community cultural and leisure services of the older adults has become increasingly prominent. The research on the influencing factors of the utilization of community cultural and leisure services of the older adults can help improve the service effect and enhance the quality of life of the older adults. Based on Anderson's model, we constructed an analytical framework of the influencing factors of the utilization of community cultural and leisure services for the older adults from both the supply and demand sides, and then used Poisson regression method to empirically test the analytical framework based on the survey data of three cities in Shaanxi Province in 2019.

\section{Results}

The results found that supply-side factors significantly influenced the utilization of community cultural and leisure services by the older adults, mainly including service facility supply, service content supply, and service location accessibility; demand-side factors significantly influenced the utilization of community cultural and leisure services by the older adults, mainly including service acceptability, service satisfaction, and service need. The study also found that, unlike the results of previous studies, the use of community cultural and leisure services by older adults was not constrained by economic level.

\section{Conclusions}

Both supply-side factors and demand-side factors significantly affect the utilization of community spiritual culture services by the older adults. In strengthening and improving the supply of community cultural and leisure services, the previous "top-down" and "service-centered" approach should be changed to a "bottom-up" and "demand-centered" approach. In the past, the supply of community spiritual culture services should be changed from a "top-down" and "service-centered" approach to a "bottom-up" and "demand-centered" approach, and attention should be paid to the urban-rural differences in supply.

\section{Introduction}

\subsection{Background}

By the end of 2019, China's older adults population aged 60 and above reached 253.88 million, accounting for $18.1 \%$ of the total population, much higher than the UN's statistical standard of $10 \%$ of the population aging[1]. Relevant data show that China's population aged 60 and above is expected to exceed 300 million in 2025, 400 million in 2033, and will reach a peak of 487 million in 2053[2]. Along 
with the increasing number of older adults, the demand for older adults services is also expanding. At the same time, along with socialism with Chinese characteristics entering a new era, the demand for older adults services in China is constantly transforming and upgrading, showing a situation where basic physiological needs and spiritual and cultural needs are equally important[3]. As the older adults move from society to family after retirement, the change of environment and role has caused more and more older adults psychological quality to weaken and their demand for Cultural and Leisure Services to become more and more urgent[4]. The "Thirteenth Five-Year Plan" for the development of the national older adults and the construction of the older adults system points out that "to improve the older adults service system, enrich the spiritual and cultural life of the older adults, the development of older adults education, and the prosperity of older adults culture."

In recent years, along with the accelerated development of population aging in China, community older adults care services have received more and more attention from the government and the society. Under the guidance of government policies and market promotion, community older adults services in China have been developed rapidly, and some urban communities have even achieved full coverage of community older adults service sites[5]. Community older adults services include life care, medical care, cultural entertainment, spiritual comfort, active aging, and rights protection, which are all urgently needed to be satisfied for the older adults. However, the utilization level of community older adults services for the older adults is generally low, and the imbalance between supply and demand is becoming more and more serious, and so is the utilization of community cultural and leisure services[6]. First, the mismatch between service content and demand has led to the dilemma of "poor supply" and "poor demand" at the same time, and the supply of community cultural and leisure services mainly focuses on the most basic services such as chess and card activities, calligraphy and painting activities, and lacks senior classes, knowledge lectures, intelligent recreational activities[7]. Secondly, the services lack specialization and are difficult to meet the needs of the older adults. At present, most studies on the factors affecting the utilization of community older adults services discuss demand-side factors such as economic level, health status, family support, and lack discussions on supply-side factors such as service supply and service price, while studies on the utilization of community cultural and leisure services mainly stay at the theoretical level, with a lack of empirical studies[8]. Service supply and service demand are the prerequisites for effective service utilization, and thus determine whether service effectiveness can be generated. In order to better break the imbalance between supply and demand, improve the effectiveness of community older adults services, and promote the healthy and sustainable development of community older adults services, it is necessary to investigate the factors influencing the utilization of community cultural and leisure services from both the supply and demand sides[9].

Accordingly, this study draws on Anderson's model to construct an analytical framework for the factors influencing the utilization of community cultural and leisure services for the older adults. Based on the questionnaire survey data in Shaanxi Province, the Poisson regression method is used to empirically analyze the key factors influencing the utilization of community cultural and leisure services for the older adults from both the supply and demand sides, in order to draw insights for the future development of community cultural and leisure services. 


\section{2 literature review}

Scholars have studied the factors influencing the utilization of community-based senior care services for older adults, focusing on overall community-based senior care service utilization, or the utilization of medical care services among them. In terms of overall community older adults service utilization, the factors that influence the utilization of older adults services are mainly gender, age, residence style, financial status, receipt of Medicaid, and health status[10][11][12][13][14]. Meanwhile, related studies show that older adults who receive support from informal caregivers such as children are more likely to use community older adults care services[15]; the more adequate social capital (social participation, volunteering, sense of belonging, social trust, etc.), the more likely older adults are to use older adults care services[16]; perceived service need and service knowledge/perception are important factors influencing older adults care service utilization[17][18]; service supply and service quality are the practical constraints for the elderly to use elderly care services[19]; socio-cultural factors may lead to urban-rural differences in the utilization of older adults care services, such as the perceptions of older adults towards communitybased older adults care services and formal support[20].

In terms of health care utilization, scholars have mainly used the Anderson Health Care Utilization Model to analyze the factors influencing the utilization of health care services. Scholars' findings suggest that older adults with poorer health status (such as self-reported health, number of chronic diseases, overweight or obese) are more likely to use health care services [21][22][23][24]; the more intergenerational support (financial support, caregiving support, emotional support from children), the more older adults use health care services[25][26]; the economic level constrains older adults' use of health care services[27][28][29]; the type of health insurance has a significant impact on the level and frequency of health care services for older adults[30][31][32]; the accessibility of community health care facilities is an important factor influencing the use of health care services for older adults[33].

According to the literature, first of all, few scholars have studied the factors influencing the utilization of community-based Cultural and Leisure Services for the older adults. However, the demand for Cultural and Leisure Services of the older adults in China is becoming more and more prominent, and the demand for older adults services has changed from a single basic physical need to both basic physical needs and spiritual and cultural needs. Secondly, existing studies have focused on demand-side factors and relatively neglected the influence of supply-side factors on the service utilization of the older adults. Therefore, this study intends to focus on community cultural and leisure services and investigate the key factors affecting the utilization of community spiritual services for the older adults from both supply and demand side perspectives.

\subsection{Analysis Framework}

The Anderson model was created by American scholar Ronald Anderson in 1968 and was originally used to analyze the factors influencing the utilization of home health services. The fourth revision of the Anderson model in 2000 renamed the "environment" dimension and the "demographic" dimension as the "situational characteristics" dimension and the "personal characteristics" dimension, respectively, and 
expanded the "situational characteristics" dimension to be the same as the "personal characteristics" dimension. The "situational characteristics" dimension is expanded into the same structure as the "personal characteristics" dimension, i.e., dispositional factors, enabling resources, and need factors[34] [35]. Thus, the Anderson model consists of four dimensions: situational characteristics, personal characteristics, medical behaviors, and medical outcomes, making the model more complex and complete. The situational characteristics dimension refers to the external environment. The personal characteristics dimension refers to the factors that predispose people to use medical services before the onset of disease, including demographic factors, social structural factors, and health beliefs; the enabling resources refer to the factors that ensure people's access to medical services, including personal resources, family resources, and community resources; and the need factors are the direct reasons for people to use medical services, including perceived health status and assessment of health status. Medical behavior dimension, including individual self-care, medical service process and medical service utilization. The medical outcome dimension, which includes perceived health status, assessed health status, and patient satisfaction, reflects the subjective evaluation of the individual's health care outcomes, and the health care outcomes have a negative impact on the individual's health care utilization behavior[35].

Anderson's model has become the most widely used theoretical model in health care utilization research[36] and is also applicable to analyze the influencing factors of psycho-cultural service utilization. It has been pointed out that, as a bridge between supply and demand of services, health care utilization is mainly influenced by supply-related and demand-related factors, in addition to individual characteristics[37][36]. This provides a more systematic approach to explore the determinants of health care service utilization and may overcome the shortcomings of Anderson's model. Therefore, this paper adopts this new perspective by reconstructing the Anderson model using the 2000 version of the Anderson model as the base model and considering only the individual characteristics, medical behavior, and medical outcome dimensions. In this study, the propensity factors are invariable and cannot be intervened[38][34], which can be used as control variables in this study[39], including demographic characteristics such as age and gender and social structural characteristics such as education level and household registration; community resources in the enabling factors are used as supply-side factors, resources of Cultural and Leisure Services for the older adults provided by the community, and are appropriately refined and extended, including service facility supply, service content; finally, the perceived service needs are used to measure the Cultural and Leisure Services needs of the older adults instead of the health status in the original model, and they are combined with the individual and family resources in the enabling factors and the satisfaction of the results in the "medical outcomes" in the original model as the demand-side factors, including Service need, service acceptability, economic level, and service satisfaction.

From the supply side, service supply is a prerequisite for the use of community cultural and leisure services for the older adults, including the supply of service facilities and the supply of service contents. On the basis of adequate service supply, scholars point out that the accessibility of service location and 
the reasonableness of service fees significantly affect the service utilization of the older adults[40][41] [42]. Therefore, this paper proposes the following research hypotheses.

\section{H1: Supply-side factors significantly affect the utilization of community cultural and leisure services for the older adults.}

H1a: The supply of service facilities significantly and positively affects the use of community cultural and leisure services for the older adults.

H1b: The supply of service content significantly and positively affects the use of community cultural and leisure services for the older adults.

H1c: Service location accessibility significantly and positively affects the utilization of community cultural and leisure services for the older adults.

H1d: Reasonableness of service fees significantly and positively affects the utilization of communitybased Cultural and Leisure Services for the older adults.

From the demand side, service need is the direct motivation for the older adults to utilize community cultural and leisure services, and at the same time, the conversion of this potential need into actual demand is also directly influenced by factors such as service acceptability, economic level, and the feedback influence of service satisfaction[43][44][45][18]. Therefore, this paper proposes the following research hypothesis.

\section{H2: Demand-side factors significantly affect the utilization of community-based Cultural and Leisure Services for the older adults.}

H2a: Service acceptability significantly and positively affects the use of community cultural and leisure services for the older adults.

H2b: Service satisfaction significantly and positively affects the use of community cultural and leisure services for the older adults.

H2c: Service need significantly and positively influences the utilization of community cultural and leisure services for the older adults.

H2d: Economic level significantly and positively influences the utilization of community cultural and leisure services for the older adults.

In summary, the Anderson model of health care service utilization was reconstructed from both the supply and demand sides to establish an analytical framework of factors influencing the utilization of community-based cultural and leisure services for the older adults, as shown in Fig. 1.

\section{Method}




\subsection{Data source}

The data of this study come from the field research data of the subject group, and this survey adopts stratified random sampling method, according to the regional distribution of Shaanxi Province, Yan'an City, Baoji City and Hanzhong City are selected as the first stratum, 2 counties (districts) in each city are randomly selected as the second stratum, a total of 6 counties (districts), then 2 street offices (townships) are randomly selected from each county (district) as the third stratum, a total of 12 street offices (townships), and finally 2 communities (village groups) are randomly selected from Each street office (township) randomly selected 2 communities (village groups) as the fourth layer, a total of 24 communities (village groups), to conduct the survey. The survey targets the older adults population aged 60 and above, and the survey covers many aspects such as old-age care, medical care, old-age service and old-age products, among which, old-age service covers the demand and supply of old-age service and evaluation of old-age service for the older adults, with a total of 948 valid questionnaires. In this paper, we select the data of cultural and recreational services part of the demand and supply of older adults services, eliminate the samples of institutional older adults care institutions services and key variables missing, and finally get 683 valid samples.

This study was approved by the Department of Social Sciences of the Ministry of Education, PRC and the Medical Ethics Committee of Health Science Center of Xi 'an Jiaotong University (Approval Number 2016 - 416). The ethics committee approves the procedure for the verbal consent, which is allowed for social investigation not involving any biological or medical experiment. Before data collection, we orally introduced the background, content and purpose of the study to respondents and assured them that the data did not involve any personal privacy information and were for research only. Only when the respondents confirmed that they were willing to participate in this survey, our investigators began the investigation. All questionnaires were completed anonymously and all procedures performed in the study were in accordance with the ethical standards.

\subsection{Variables selection}

\section{(1) Dependent variable: community cultural and leisure services Utilization}

The utilization of community cultural and leisure services is defined as the number of older adults who have used the cultural and recreational services provided by the community, which is measured by asking the older adults "the content of cultural and recreational services provided by the community (multiple choice)", including five items of older adults interest groups, cultural performances, chess and card activities, knowledge lectures, and intelligent older adults recreational services, and the values are A value of 1 means that the older adults have used the service, and a value of 0 means that the older adults have not used the service. Finally, the scores of each service are summed up to obtain the spiritual cultural service utilization variable, with a value range of $0 \sim 5$.

\section{(2) Independent variables}


According to the analysis framework of the study, the independent variables include two main categories. The first category is the supply side, which is mainly measured by service facility supply, service content supply, service location accessibility, and service fee reasonableness. The service facilities mainly include senior activity centers, chess and card rooms, reading rooms, painting and calligraphy rooms and senior fitness rooms, and the service contents mainly include senior interest groups, cultural performances, chess and card activities, knowledge lectures and smart senior recreational activities. "The scores of each service facility/service content provided were summed up to obtain two variables, namely, service facility supply and service content supply, with the values ranging from 0 to 5 . The second category is the demand side, mainly measured by service acceptability, service satisfaction, service need and economic level. The second category is the demand side, which is measured by service acceptability, service satisfaction, service need, and economic level, where service satisfaction indicates the feedback impact of service effect. Service acceptability refers to the psychological response of the older adults to the home community service provider's network and door-to-door service, and mainly measures the degree of acceptance of the service by the older adults [19], in this study, it mainly refers to the degree of acceptance of community cultural and leisure services by the older adults, and is measured by the older adults' "willingness to participate in these recreational activities". The results were expressed by Likert scale with values from 1 to 5 ; service satisfaction refers to the degree of satisfaction of the older adults with the community cultural and leisure services provided by the community, measured by Likert scale with values from 1 to 5 ; service need includes older adults interest groups, cultural performances, chess and card activities, knowledge lectures and intelligent recreational services for the older adults, 1 means the older adults have a need for the service, 0 means the older adults do not have a need, and finally the scores were The higher the score, the greater the need, and the range of values is $0 \sim 5$. The economic level refers to the total annual income of the older adults in the previous year and is a continuous variable.

\section{(3) Control variables}

According to previous research literature, the control variables used in this paper include: age (continuous variable), gender (male, female), education level (elementary school and below, junior high school, high school/junior high school, college, undergraduate and above), type of marriage (unmarried, married, divorced, widowed), household registration (urban, rural), whether living alone, and ability to take care of oneself. The ability to take care of oneself is a composite of the respondents' scores on six indicators: eating, dressing, getting in and out of bed, going to the toilet, walking around indoors and bathing, with values from 0 to 6 . The higher the score, the worse the ability to take care of oneself. The setting and description of the variables are shown in Table 1. 
Table 1

Setting and description of variables

\begin{tabular}{|c|c|c|}
\hline $\begin{array}{l}\text { Variable } \\
\text { Classification }\end{array}$ & Variable & Variable Description \\
\hline $\begin{array}{l}\text { Dependent } \\
\text { variables }\end{array}$ & $\begin{array}{l}\text { Community cultural } \\
\text { and leisure services }\end{array}$ & $0 \sim 5$ \\
\hline \multirow{7}{*}{$\begin{array}{l}\text { Control } \\
\text { variables }\end{array}$} & Age & 60 years old and above \\
\hline & Gender & Male $=0$ (reference group), Female $=1$ \\
\hline & Education level & $\begin{array}{l}\text { Elementary school and below }=1 \text {, middle school }=2 \text {, high } \\
\text { school } / \text { junior college }=3 \text {, college }=4, \text { bachelor and above }=5\end{array}$ \\
\hline & Marriage type & $\begin{array}{l}\text { Unmarried = } 1 \text {, Married = } 2 \text { (reference group), Divorced = } 3 \text {, } \\
\text { Widowed = } 4\end{array}$ \\
\hline & $\begin{array}{l}\text { household } \\
\text { registration }\end{array}$ & Urban $=0$ (reference group), Rural = 1 \\
\hline & living alone or not & No $=0$ (reference group), Yes $=1$, \\
\hline & $\begin{array}{l}\text { Activities of daily } \\
\text { living (ADL) }\end{array}$ & $0 \sim 6$ \\
\hline \multirow[t]{4}{*}{$\begin{array}{l}\text { Supply } \\
\text { variables }\end{array}$} & $\begin{array}{l}\text { Service facility } \\
\text { supply }\end{array}$ & $0 \sim 5$ \\
\hline & $\begin{array}{l}\text { Service Content } \\
\text { supply }\end{array}$ & $0 \sim 5$ \\
\hline & $\begin{array}{l}\text { Accessibility of } \\
\text { service location }\end{array}$ & $\begin{array}{l}\text { Very inconvenient }=1 \text {, not very convenient }=2 \text {, average }=3 \text {, } \\
\text { more convenient }=4 \text {, very convenient }=5\end{array}$ \\
\hline & $\begin{array}{l}\text { Reasonableness of } \\
\text { service charges }\end{array}$ & $\begin{array}{l}\text { Very unreasonable }=1 \text {, Not very reasonable }=2 \text {, Fair }=3 \text {, More } \\
\text { reasonable }=4 \text {, Very reasonable }=5\end{array}$ \\
\hline \multirow[t]{4}{*}{$\begin{array}{l}\text { Demand } \\
\text { variables }\end{array}$} & $\begin{array}{l}\text { Service } \\
\text { acceptability }\end{array}$ & $\begin{array}{l}\text { Not willing }=1 \text {, Not very willing }=2 \text {, Indifferent }=3 \text {, More } \\
\text { willing }=4 \text {, Very willing }=5\end{array}$ \\
\hline & Service satisfaction & $\begin{array}{l}\text { Very dissatisfied }=1 \text {, not very satisfied }=2 \text {, average }=3 \text {, more } \\
\text { satisfied }=4 \text {, very satisfied }=5\end{array}$ \\
\hline & Service Needs & $0 \sim 5$ \\
\hline & Economic level & Continuous variables \\
\hline
\end{tabular}

\subsection{Analysis method}

This study used Poisson regression model for analysis based on two main considerations: first, the data distribution, like the service utilization behavior of all older adults with a Poisson distribution [3], the data on community cultural and leisure services utilization in this study also had a Poisson distribution; second, the data characteristics, the dependent variable community cultural and leisure services utilization has a range of values from 0 to 5 , which is a count variable. 
In order to analyze the direction and degree of influence of supply side and demand side on the utilization of community cultural and leisure services, four models were constructed in this paper; model 1 incorporates only control variables, model 2 incorporates both control variables and supply side factors, model 3 incorporates both control variables and demand side factors, and model 4 is a full model, incorporating both control variables, supply side and demand side factors. The specific models are as follows.

$$
\begin{aligned}
& f^{1}(p)=\alpha^{1}+\beta_{1}^{1} x_{\text {Control variables }}+\epsilon^{1} \\
& f^{2}(p)=\alpha^{2}+\beta_{1}^{2} x_{\text {Control variables }}+\beta_{2}^{2} \text { supply }+\epsilon^{2} \\
& f^{3}(p)=\alpha^{3}+\beta_{1}^{3} x_{\text {Control variables }}+\beta_{2}^{3} \text { demand }+\epsilon^{3} \\
& f^{4}(p)=\alpha^{4}+\beta_{1}^{4} x_{\text {Control variables }}+\beta_{2}^{4} x_{\text {supply }}+\beta_{3}^{4} \text { demand }+\epsilon^{4}
\end{aligned}
$$

\section{Results}

\subsection{Demographic characteristics and overall service utilization}

Among the surveyed older adults, the youngest was 60 years old and the oldest was 92 years old, with an average age of 70.41 years old; the ratio of men to women was about $0.6: 1$, with more female older adults than male older adults; in terms of education level, the percentage of older adults with elementary school education and below reached $43.48 \%$, while those with college education and above only accounted for about $8 \%$, and the overall education level of the surveyed older adults was low; in terms of household registration, the ratio between urban and rural households was 1.3:1, with slightly more older adults living in urban households than in rural households; in terms of self-care ability, the mean value of $A D L$ was 0.05 , meaning that the majority of older adults were not physically impaired; in terms of living alone, the ratio between older adults living alone and those not living alone was about 0.2:1, with most of the surveyed older adults living with their children and other family members; in terms of marriage type, the largest number of older adults were married, accounting for $71.5 \%$. In terms of marriage type, the largest number of older adults are married, accounting for $71.60 \%$, followed by widowed, accounting for $25.48 \%$. Regarding the use of community cultural and leisure services, $39.39 \%$ of the older adults had not used community cultural and leisure services, $22.98 \%$ had used one, $22.98 \%$ had used two, and $14.65 \%$ had used three or more, so the overall use of community cultural and leisure services by the surveyed older adults was good, and more than half of the older adults had used the services. Descriptive statistics are shown in Table 2. 
Table 2

Descriptive statistics

\begin{tabular}{|c|c|c|c|}
\hline Variables & Classification & Number & $\begin{array}{l}\text { Frequency } \\
\text { (\%) }\end{array}$ \\
\hline \multirow[t]{2}{*}{ Age } & 60 years old and above & \multicolumn{2}{|c|}{ Mean value.70.41 } \\
\hline & & \multicolumn{2}{|c|}{$\begin{array}{l}\text { Standard } \\
\text { deviation.7.08 }\end{array}$} \\
\hline \multirow[t]{2}{*}{ Gender } & Male & 265 & 38.80 \\
\hline & Female & 418 & 61.20 \\
\hline \multirow[t]{5}{*}{ Education } & $\begin{array}{l}\text { Elementary school and } \\
\text { below }\end{array}$ & 297 & 43.48 \\
\hline & Junior high school & 193 & 28.26 \\
\hline & $\begin{array}{l}\text { High school/junior high } \\
\text { school }\end{array}$ & 138 & 20.21 \\
\hline & College & 38 & 5.56 \\
\hline & Bachelor's degree or above & 17 & 2.49 \\
\hline \multirow[t]{4}{*}{ Marriage } & Unmarried & 10 & 1.46 \\
\hline & Married & 489 & 71.60 \\
\hline & Divorced & 10 & 1.46 \\
\hline & Widowed & 174 & 25.48 \\
\hline \multirow[t]{2}{*}{ Household registration } & Urban & 388 & 56.81 \\
\hline & Rural & 295 & 43.19 \\
\hline \multirow[t]{2}{*}{ Whether living alone } & No & 557 & 81.55 \\
\hline & Yes & 126 & 18.45 \\
\hline \multirow[t]{2}{*}{ Activities of daily living (ADL) } & $0 \sim 6$ & \multicolumn{2}{|c|}{ Mean value. 0.05} \\
\hline & & \multicolumn{2}{|c|}{$\begin{array}{l}\text { Standard } \\
\text { deviation.0.43 }\end{array}$} \\
\hline \multirow{4}{*}{$\begin{array}{l}\text { Community Cultural and Leisure Services } \\
\text { utilization }\end{array}$} & 0 & 269 & 39.39 \\
\hline & 1 & 157 & 22.98 \\
\hline & 2 & 157 & 22.98 \\
\hline & 3 & 68 & 9.96 \\
\hline
\end{tabular}




\begin{tabular}{|cccc|}
\hline Variables & Classification & Number & Frequency \\
(\%)
\end{tabular}

\subsection{Analysis of regression results}

Table 3 shows the results of the Poisson regression analysis, where the dependent variable is the utilization of community cultural and leisure services, model 1 incorporates only the control variables, models 2 and 3 are the results of incorporating supply-side and demand-side factors, respectively, based on the control variables, and model 4 is the full model. Although there may be covariance among the variables, the statistics show that the four models do not have serious covariance problems (see the notes to Table 3), which can be used as the basis for analysis.

(1) Test of the impact of supply-side factors on the utilization of community cultural and leisure services for the older adults

Table 3 Model 1 incorporates only control variables, and the results show that age, literacy, and household registration are significant and affect the utilization of community cultural and leisure services for the older adults, while the effects of gender, type of marriage, whether living alone, and ability to take care of oneself sexually are not significant, and literacy is highly significant in all four models. Model 2 examined the effects of supply-side factors on the utilization of community cultural and leisure services for the older adults based on control variables, and the results showed that the supply of service facilities, the supply of service content, and the accessibility of service location had significant positive effects on the utilization of community cultural and leisure services for the older adults (coef. $=0.103, p<0.001$; coef. $=0.306, p<0.001$. coef. $=0.129, p<0.001$ ), the effect of service fee reasonableness was not significant (coef. $=0.091, p>0.05$ ) and the result remained robust in the subsequent full model 4 (coef. $=0.074, p<0.05$; coef. $=0.306, p<0.001$; coef. $=0.076, p<0.05$. (coef. $=0.060, p>0.05$ ). This indicates that the more adequate the supply of service facilities, the more helpful it is for the older adults to use community cultural and leisure services; the more adequate the supply of service contents, the more likely the older adults will use community cultural and leisure services; the more convenient and accessible the location of services, the more likely the older adults will use community cultural and leisure services. This verifies the hypothesis 1 of this paper: supply-side factors significantly affect the use of spiritual culture services by the older adults, further verifying hypotheses $\mathrm{H} 1 \mathrm{a}, \mathrm{H} 1 \mathrm{~b}$ and $\mathrm{H} 1 \mathrm{c}$, and hypothesis $\mathrm{H} 1 \mathrm{~d}$ does not pass the verification.

(2) Test of the influence of demand-side factors on the utilization of community cultural and leisure services for the older adults

Table 3 Model 3 examined the influence of demand-side factors on the utilization of community cultural and leisure services for the older adults based on the control variables, and the results showed that 
service acceptability, service satisfaction, and service need had significant positive effects on the utilization of community cultural and leisure services for the older adults (coef. $=0.224, p<0.001$; coef. $=0.291, p<0.001$; coef. $=0.090, p<0.001)$, the effect of economic level was not significant (coef. $=-0.001, p>0.05$ ) and the result remained robust in the subsequent full model 4 (coef. $=0.175, p<$ 0.001 ; coef. $=0.106, p<0.001$; coef. $=0.092, p<0.001$; coef. $=(-0.001, p>0.05)$. This indicates that the more receptive the older adults are to the service, the more likely they are to utilize the cultural and leisure services; the more satisfied the older adults are with the service, the more likely they are to utilize the cultural and leisure services; and the greater the need for the cultural and leisure services, the more likely they are to utilize the service. This verifies the hypothesis 2 of this paper: demand-side factors significantly affect the utilization of spiritual culture services by the older adults, and further verifies hypotheses $\mathrm{H} 2 \mathrm{a}, \mathrm{H} 2 \mathrm{~b}$, and $\mathrm{H} 2 \mathrm{c}$, and hypothesis $\mathrm{H} 2 \mathrm{~d}$ does not pass the verification. 
Table 3

Results of Poisson regression analysis for the use of community cultural and leisure services for the older adults

\begin{tabular}{|c|c|c|c|c|}
\hline Variables & Model 1 & Model 2 & Model 3 & Model 4 \\
\hline Age & $-0.023 * \star \star$ & $-0.014^{\star}$ & -0.011 & -0.007 \\
\hline Gender & -0.074 & -0.015 & -0.071 & -0.008 \\
\hline Education level & $0.197 * \star \star$ & $0.117^{\star *}$ & $0.165^{\star \star \star}$ & $0.103^{\star *}$ \\
\hline \multicolumn{5}{|l|}{ Marriage type } \\
\hline Unmarried & -0.072 & -0.148 & -0.050 & -0.193 \\
\hline Divorced & 0.285 & -0.114 & 0.455 & -0.011 \\
\hline Widowed & 0.224 & 0.065 & 0.155 & -0.031 \\
\hline household registration & $0.262^{\star \star}$ & 0.091 & $0.279 * * \star$ & 0.169 \\
\hline living alone or not & -0.024 & 0.037 & -0.057 & 0.062 \\
\hline Activities of daily living (ADL) & -0.149 & $-0.237^{\star}$ & -0.112 & -0.201 \\
\hline Service facility supply & & $0.103^{\star \star *}$ & & $0.074^{*}$ \\
\hline Service content supply & & $0.306^{* \star *}$ & & $0.306 * \star \star$ \\
\hline Accessibility of service location & & $0.129 * \star \star$ & & $0.076^{*}$ \\
\hline Reasonableness of service charges & & 0.091 & & 0.060 \\
\hline Service acceptability & & & $0.224^{\star \star \star}$ & $0.175^{\star \star \star}$ \\
\hline Service satisfaction & & & $0.291 * * \star$ & $0.106^{\star \star}$ \\
\hline Service Needs & & & $0.090 * \star \star$ & $0.092^{\star * *}$ \\
\hline Economic level & & & -0.001 & -0.001 \\
\hline F-value & $61.81 * \star \star$ & $370.03 * \star \star$ & $258.43^{\star \star \star}$ & $442.68^{\star \star \star}$ \\
\hline Tolerance (Tolerance) & $>0.471749$ & $>0.363692$ & $>0.458214$ & $>0.357269$ \\
\hline Variance inflation factor (VIF) & $<2.12$ & $<2.75$ & $<2.18$ & $<2.80$ \\
\hline R2 & 0.0306 & 0.1835 & 0.1282 & 0.2195 \\
\hline Effective sample size (person) & 683 & 683 & 683 & 683 \\
\hline \multicolumn{5}{|c|}{$\begin{array}{l}\text { Note: (1) Significance, } * P<0.05, * * P<0.01, * * * P<0.001 \text {; (2) Tolerance (Tolerance) and variance } \\
\text { inflation factor (VIF) are both tests of covariance of independent variables, and the tolerance of the } \\
\text { above six models are all much larger than } 0.10 \text {, and the variance inflation factor is much smaller than } \\
10 \text {, indicating that there is no serious covariance between the independent variables. }\end{array}$} \\
\hline
\end{tabular}




\section{Discussion}

This study analyzed the factors influencing the use of community cultural and leisure services for the older adults from both the supply and demand sides through field research data, and the findings verified two research hypotheses that supply and demand significantly affect the use of community cultural and leisure services for the older adults.

First, the utilization of community cultural and leisure services is significantly influenced by literacy level. Among all the control variables, literacy level is highly significant in models 1 to 4 , i.e., the higher the literacy level, the more likely the older adults are to use community cultural and leisure services, and to some extent, it can be considered that the current utilization of community cultural and leisure services in China has a "pro-intellectual" tendency. On the one hand, education can improve the income level and economic independence of the older adults and enhance their purchasing power, thus promoting their use of community cultural and leisure services; on the other hand, the improvement of education can expand the interpersonal circle of the older adults and broaden their information access.

Second, the utilization of community cultural and leisure services is not bound by the economic level. The research results show that the effect of economic level on the utilization of community cultural and leisure services for the older adults is insignificant, and this research result is contrary to the results of previous studies on the utilization of social older adults services. On the one hand, the supply cost of community cultural and leisure services for the older adults is low, and on the other hand, the consumption ability of the older adults gradually increases with the improvement of the economic level. Further divided into urban and rural areas, among the rural older adults, those with an annual income of less than 10,000 RMB accounted for more than $50 \%$ of the surveyed rural older adults, and the economic level remains a factor affecting the utilization of community cultural and leisure services among the rural older adults because they have less savings and are still engaged in agricultural labor in their later years. The government should pay attention to the spiritual and cultural needs of the older adults in need, while ensuring their basic material needs, as spiritual culture affects their psychological health, which in turn affects their physical health. The government should play a bottom-up role to provide community cultural and leisure services for the older adults who are affected by the economic level.

Third, the utilization of spiritual culture services is significantly influenced by supply-side factors.

Research shows that the more service facilities are supplied, the more service content is supplied, and the higher the accessibility of service location, the higher the level of spiritual cultural service utilization of the older adults. The supply of cultural and leisure services for the older adults in cities is more adequate, and the service location is mainly in the community, while the village group in rural areas contains a larger area, and often there is only one activity point in a village group, and the facilities are simple and far away. As mentioned above, the supply-side factor of the reasonableness of service charges does not have a significant impact on the utilization of cultural and leisure services for the older adults. As mentioned above, the supply cost of cultural and leisure services for the older adults is low, and the consumption ability of the older adults is increasing, so the economy no longer constrains the utilization 
behavior of cultural and leisure services for the older adults [46]. The supply of cultural and leisure services in the community is far from meeting the needs of the elderly, and the inequality in the supply of cultural and leisure services in urban and rural communities is very seriously [47]. At the same time, related studies show that the more specialized and space and equipment required, the lower the coverage rate of home community older adults service programs [48]. The field research of the research group found that the supply of community cultural and leisure services is limited to simple services such as chess and card activities, and some even only provide venues for activities, lacking higher-level services such as knowledge lectures, senior classes and senior universities. Meanwhile, the quantity and quality of spiritual cultural service supply in rural areas are lower than those in urban areas, and the remote location of services often hinders rural older adults from using spiritual cultural service facilities.

Fourth, the use of cultural and leisure services is significantly influenced by demand-side factors. The results of the study show that the higher the acceptance of cultural and leisure services by the older adults, the more satisfied they are with the services, the greater the service need, and the greater the possibility of their using the services. Further research on service need factors by urban and rural areas shows that among urban older adults, those with cultural and leisure services needs account for $64 \%$ of the urban older adults surveyed, and among rural older adults, those with service needs account for $58 \%$ of the rural older adults surveyed, which shows that the spiritual and cultural needs of rural older adults are similar to those of urban older adults, and the spiritual and cultural needs of rural older adults may explode in the future The demand side factors The effect of economic level among the demand side factors is not significant, but negative, which indicates to some extent that the higher the economic level of the older adults, the more they may tend to choose professional market-based services. A large number of studies have shown that the mismatch between demand and supply is the main reason for the low utilization of community older adults services in China[49], and also the main reason for the low utilization of community cultural and leisure services in China. This indicates that on the one hand, the spiritual needs of the older adults are not met, and on the other hand, a part of the current supply of community cultural and leisure services is "idle", i.e., there is a general oversupply of services in a low supply ratio. In our field research, the older adults generally report that the community spiritual and cultural facilities are single, the services are simple, and there is a lack of professional teachers to guide them, which makes it difficult to meet their needs. Therefore, the supply of community cultural and leisure services should consider the individual needs of different levels of older adults, and provide the most basic community cultural and leisure services while considering the specialized needs of higher-level older adults.

\section{Conclusions}

Based on the improved Anderson model, this paper constructs an analytical framework for the factors influencing the utilization of community cultural and leisure services for the older adults from both the supply and demand sides. Using questionnaire survey data in Shaanxi Province in 2019, Poisson regression method is applied to empirically test the analytical framework. It was found that both supplyside and demand-side factors significantly affect the utilization of community cultural and leisure 
services for the older adults. Specifically, the supply-side factors of service facility supply, service content supply, and service location accessibility had significant effects, while the demand-side factors of service acceptability, service satisfaction, and service need had significant effects. The study also found that, unlike the results of previous studies, the utilization of community cultural and leisure services for the older adults was not constrained by economic level.

The article suggests to improve the supply level and quality of community cultural and leisure services for the older adults. First, adhere to the concept of demand-oriented service supply. In strengthening and improving the supply of community cultural and leisure services for the older adults, we should change the previous "top-down" and "service-centered" thinking to "bottom-up" and "demand-centered". "When carrying out cultural and leisure services, we should conduct demand surveys and assessments, and strive to supply services from the perspective of the actual needs of the older adults, so as to improve the efficiency of service utilization. Second, the supply of cultural and leisure services should be different between urban and rural areas. The supply of spiritual culture services for the urban older adults is in place, so we should focus on the specialization of service supply, i.e., from "available" to "excellent"; the lack of spiritual culture services for the rural older adults, and the future demand for spiritual culture for the rural older adults may grow explosively, so we should focus on At the same time, the accessibility of services is also an important factor affecting the use of spiritual culture services for rural older adults. Finally, we should improve the subsidy system and expand the scope of services purchased by the government. On the one hand, for some older adults with low income and insufficient ability to pay, reasonable subsidy standards should be set according to their health and income levels, so that lowincome older adults can also use community cultural and leisure services; on the other hand, the scope of government purchased services should be expanded to include community cultural and leisure services, so as to improve the utilization rate of services.

\section{Limitations}

The limitations of this study are, firstly, confined to data limitations, which only focus on the influencing factors of spiritual culture service utilization in Shaanxi Province and lack of typicality; secondly, the inclusion of explanatory variables is not sufficient and the explanatory power of the model is not high. The future study can work on 2 aspects: (1) further expand the scope of the study, field research in developed eastern regions to verify and enrich the existing study; (2) on the selection of indicators for the utilization of community cultural and leisure services of the older adults, the indicators will be continuously adjusted and improved through more detailed interview research in the future to provide a theoretical basis for enriching the analytical framework for the utilization of community cultural and leisure services of the older adults.

\section{Abbreviations}

ADL: Activities of daily living 


\section{Declarations}

Acknowledgments: Thanks to the survey group of Xi'an Jiaotong University for the help in data collecting. Any student participating in the survey can use the data for research.

Author Contributions: All authors participated in the questionnaire survey. Q.N(Qing Niu). C.Z. (Chi Zhang), Z.Y.(Zhao Yu) and S.Z. (SiFeng Zhang) participated in the design and conceptualization of the study. Q.N(Qing Niu) ,Z.Y.(Zhao Yu) and S.Z. reviewed literature. C.Z. (Chi Zhang) and S.Z. analyzed the data and interpreted the statistical results. Q.N(Qing Niu) drafted the manuscript. Q.N(Qing Niu), Z.Y. (Zhao Yu) and S.Z. (SiFeng Zhang) were involved in critically revising the manuscript. All authors have read and agreed to the published version of the manuscript.

Funding: This study was funded by the Major Projects of Philosophy and Social Science Research of the Ministry of Education (18JZD045), National Social Science Fund of China (16AZD028). The funding bodies had no further involvement in the research process, and they will continue to fund follow-up research.

Availability of data and materials[The datasets used during the current study are available from the corresponding author on reasonable request.

Statement for guidelines: all methods were performed in accordance with the relevant guidelines and regulations.

Ethics approval and consent to participate[This study was approved by the Department of Social Sciences of the Ministry of Education, PRC and the Medical Ethics Committee of Health Science Center of Xi 'an Jiaotong University (Approval Number 2016-416). The ethics committee approves the procedure for the verbal consent, which is allowed for social investigation not involving any biological or medical experiment. Before data collection, we orally introduced the background, content and purpose of the study to respondents and assured them that the data did not involve any personal privacy information and were for research only. Only when the respondents confirmed that they were willing to participate in this survey, our investigators began the investigation. All questionnaires were completed anonymously and all procedures performed in the study were in accordance with the ethical standards.

Consent for publication!"Not applicable".

Competing interests $\square$ The authors declare that they have no competing interests.

\section{References}

1. National Bureau of Statistics. Statistical Bulletin of the People's Republic of China on National Economic and Social Development 2019. http://www.stats.gov.cn/tjsj/zxfb/202002/t20200228_1728913.html 
2. Ministry of Civil Affairs of the People's Republic of China. Implement a national strategy to actively respond to an aging population.

http://www.mca.gov.cn/article/xw/mzyw/202012/20201200031204.shtml

3. Lunder U, Furlan M, Simonic A. Spiritual needs assessments and measurements. Current Opinion in Supportive \& Palliative Care. 2011;5(3):273-8.

4. Sivertsen N, Harrington A, Hamiduzzaman M. Exploring aboriginal aged care residents' cultural and spiritual needs in south australia. BMC Health Services Research. 2019;19.

5. Liu ZW, Yu Y, Fang L, Hu M, Zhou L, Xiao SY. Willingness to receive institutional and communitybased eldercare among the rural elderly in china. Plos one. 2019;14(11).

6. Cho GS, Yi ES. Analysis on leisure patterns of the pre-elderly adults. Journal of exercise rehabilitation. 2013;9(4):438-45.

7. Oner O, Klaesson J. Location of leisure: the New Economic Geography of leisure services. LEISURE STUDIES. 2017;36(2):203-219.

8. Ghosh S, Husain Z. Economic independence, family support and perceived health status of the elderly: recent evidence from india. Asia-Pacific population journal/United Nations.2010;25(1):47-77.

9. Chao JQ, Wang YM, Xu H, Yu Q, Jiang LL, Tian L, Xie WY, Liu P. The effect of community-based health management on the health of the elderly: a randomized controlled trial from china. BMC Health Services Research. 2012;12.

10. McDougle LM, Meyer S, Handy F. Individual- and Contextual-Level Factors Affecting the Use of Social Support Services among Older Adults. JOURNAL OF SOCIAL SERVICE RESEARCH. 2018;44(1):108118.

11. Sonnega A, Robinson K, Levy H. Home and community-based service and other senior service use: Prevalence and characteristics in a national sample. HOME HEALTH CARE SERVICES QUARTERLY. 2017;36(1):16-28.

12. Cohen-Mansfield J, Dakheel-Ali M, Jensen B. Predicting Service Use and Intent to Use Services of Older Adult Residents of Two Naturally Occurring Retirement Communities. SOCIAL WORK RESEARCH. 2013;37(4):313-326.

13. Park S, Kim B, Kwon E, Lee H. Trajectories of Community-Based Service Use: The Importance of Poverty and Living Arrangements. JOURNAL OF GERONTOLOGICAL SOCIAL WORK. 2017;60(5):355376.

14. Lehning AJ, Kim MH, Dunkle RE. Facilitators of Home and Community-Based Service Use by Urban African American Elders. JOURNAL OF AGING AND HEALTH. 2013;25(3):439-458.

15. van Bilsen PMA, Hamers JPH, Don AAM, Groot W, Spreeuwenberg C. The use of social services by community-dwelling older persons who are at risk of institutionalization: a survey. EUROPEAN JOURNAL OF AGEING. 2010;7(2):101-109.

16. Peng CM, Burr JA, Kim K, Lu N. Home and Community-Based Service Utilization among Older Adults in Urban China: The Role of Social Capital. JOURNAL OF GERONTOLOGICAL SOCIAL WORK. 
2020;63(8):790-806.

17. Liu YL. Aging service need and use among chinese american seniors: intragroup variations. Journal of Cross-Cultural Gerontology. 2003;18(4):273-301.

18. Crist JD, Woo SH, Choi M. A Comparison of the Use of Home Care Services by Anglo-American and Mexican American Elders. Journal of Transcultural Nursing. 2007;18(4):339-348.

19. Yu Z, Wang LJ, Ariyo T. Supply and Demand-Related Decisive Factors in the Utilization of NonMedical Community Healthcare Services among Elderly Chinese. INTERNATIONAL JOURNAL OF ENVIRONMENTAL RESEARCH AND PUBLIC HEALTH. 2021;18(1).

20. Sun F. Community Service Use by Older Adults: The Roles of Sociocultural Factors in Rural-Urban Differences. JOURNAL OF SOCIAL SERVICE RESEARCH. 2011;37(2):124-135.

21. Han KM, Ko YH, Yoon HK, Han C, Ham BJ, Kim YK. Relationship of depression, chronic disease, selfrated health, and gender with health care utilization among community-living elderly. JOURNAL OF AFFECTIVE DISORDERS. 2018;241:402-410.

22. Tsou MT. Healthcare Service Utilization and Associated Factors in Community-Dwelling Elderly in Northern Taiwan: One Medical Center's Experience. INTERNATIONAL JOURNAL OF GERONTOLOGY. 2018;12(2):144-149.

23. Hajek A, Bock JO, Konig HH. Which factors affect health care use among older Germans? Results of the German ageing survey. BMC HEALTH SERVICES RESEARCH. 2017;17.

24. Boyd PJ, Nevard M, Ford JA, Khondoker M, Cross JL, Fox C. The electronic frailty index as an indicator of community healthcare service utilisation in the older population. AGE AND AGEING. 2019;48(2):273-277.

25. Quashie NT, Pothisiri W. Rural-urban gaps in health care utilization among older Thais: The role of family support. ARCHIVES OF GERONTOLOGY AND GERIATRICS. 2019;81:201-208.

26. Gyasi RM, Phillips DR, Amoah PA. Multidimensional Social Support and Health Services Utilization Among Noninstitutionalized Older Persons in Ghana. JOURNAL OF AGING AND HEALTH. 2020;32(34):227-239.

27. Liu DP, Meng HD, Dobbs D, Conner KO, Hyer K, Li NX, Ren XH, Gao B. Cross-sectional study of factors associated with community health centre use in a recently urbanised community in Chengdu, China. BMJ OPEN. 2017;7(6).

28. Jiang $M$, Yang $G$, Fang $L Y$, Wan J, Yang $Y H$, Wang $Y$. Factors associated with healthcare utilization among community-dwelling elderly in Shanghai, China. PLOS ONE. 2018;13(12).

29. Zeng YB, Xu WQ, Chen LL, Chen F, Fang Y. The Influencing Factors of Health-Seeking Preference and Community Health Service Utilization Among Patients in Primary Care Reform in Xiamen, China. PATIENT PREFERENCE AND ADHERENCE. 2020;14:653-662.

30. Lin S. Inequities in Access: The Impact of a Segmented Health Insurance System on Physician Visits and Hospital Admissions Among Older Adults in the 2014 China Family Panel Studies. INTERNATIONAL JOURNAL OF HEALTH SERVICES. 2020;50(2):184-198. 
31. Wang ZH, Li XJ, Chen MS, Si L. Social health insurance, healthcare utilization, and costs in middleaged and elderly community-dwelling adults in China. INTERNATIONAL JOURNAL FOR EQUITY IN HEALTH. 2018;17.

32. Lin $\mathrm{YW}, \mathrm{Chu} \mathrm{CJ}$, Chen $\mathrm{Q}$, Xiao JH, Wan $\mathrm{CH}$. Factors influencing utilization of primary health care by elderly internal migrants in China: the role of social contacts. BMC PUBLIC HEALTH. 2020;20(1).

33. Hu XQ, Zhang H, Sun XS, Gu YX, Zhen XM, Gu SY, Li YY, Huang MZ, Wei JM, Dong HJ. Older adults' choices of first-contact care and related factors in Zhejiang and Qinghai Province, China. GERIATRICS \& GERONTOLOGY INTERNATIONAL. 2019;19(9):938-944.

34. Andersen RM. Revisiting the behavioral model and access to medical care: does it matter? Journal of health and social behavior. 1995;36(1):1-10.

35. Fu YY, Guo Y, Bai X, Chui EWT. Factors associated with older people's long-term care needs: a case study adopting the expanded version of the Anderson Model in China. Bmc Geriatrics. 2017;17.

36. Babitsch B, Gohl D, Lengerke TV. Re-revisiting Andersen's Behavioral Model of Health Services Use: a systematic review of studies from 1998-2011. Psycho-social medicine. 2012;9..

37. Kendig H, Mealing N, Carr R, Lujic S, Byles J, Jorm L. Assessing patterns of home and community care service use and client profiles in Australia: A cluster analysis approach using linked data. HEALTH \& SOCIAL CARE IN THE COMMUNITY. 2012;20(4):375-387.

38. Andersen RM, Davidson PL, Baumeister SE. Improving access to care in America. In Changing the U.S. Health Care System: Key Issues in Health Services, Policy, and Management; Kominski, E.F., Ed.; Jossey-Bass: San Francisco, CA, USA, 2013; pp. 33-69.

39. Lei X. Study on the satisfaction of medical services between urban and rural residents. J. Agrotech. Econ. 2019;4:16-28.

40. Chen Y, Chen H. Disparity between need and use: Reflections on delivery of community home care services. Zhejiang. Acad. J. 2017;2:30-37.

41. Fang LI, Wang Y. Current situation of the utilization of the community elderly care service and its influencing factors: a case study of Nanjing Gulou district. Population and Society. 2016;32:51-60.

42. Nelms L, Johnson V, Teshuva K, Foreman P, Stanley J. Social and health factors affecting community service use by vulnerable older people. AUSTRALIAN SOCIAL WORK. 2009;62(4):507524.

43. Zhang HF, Luo W. A study of the influence of care service resources on the demand for social care service for senior citizens. China Population Resources and Environment. 2019;29(4)168-176.

44. Guo C, Du W, Hu CH, Zheng XY. Prevalence and factors associated with healthcare service use among Chinese elderly with disabilities. JOURNAL OF PUBLIC HEALTH. 2016;38(3):E345-E351.

45. Du P, Wang Y. Determinants of utilization of social care service for older persons in China. Pop. Res. 2017;41:26-37.

46. Sun W, Aodeng S, Tanimoto Y, Watanabe M, Han JS, Wang BW, Yu LZ, Kono K. Quality of life (QOL) of the community-dwelling elderly and associated factors: A population-based study in urban areas 
of China. ARCHIVES OF GERONTOLOGY AND GERIATRICS. 2015;60(2):311-316.

47. Luo JH, Zhang XL, Jin CG, Wang DM. Inequality of access to health care among the urban elderly in northwestern China. Health Policy. 2009;93(2-3):111-117.

48. Mfphm H, Bsc EW, Frcp I, Frcgp D, Sharp D. What determines the use of home care services by elderly people? Heart Lung \& Circulation. 2010;10(5):348-360.

49. Fu XZ, Sun N, Xu F, Li J, Tang QX, He JJ, Wang DD, Sun CQ. Influencing factors of inequity in health services utilization among the elderly in China. International Journal for Equity in Health. 2018;17.

\section{Figures}

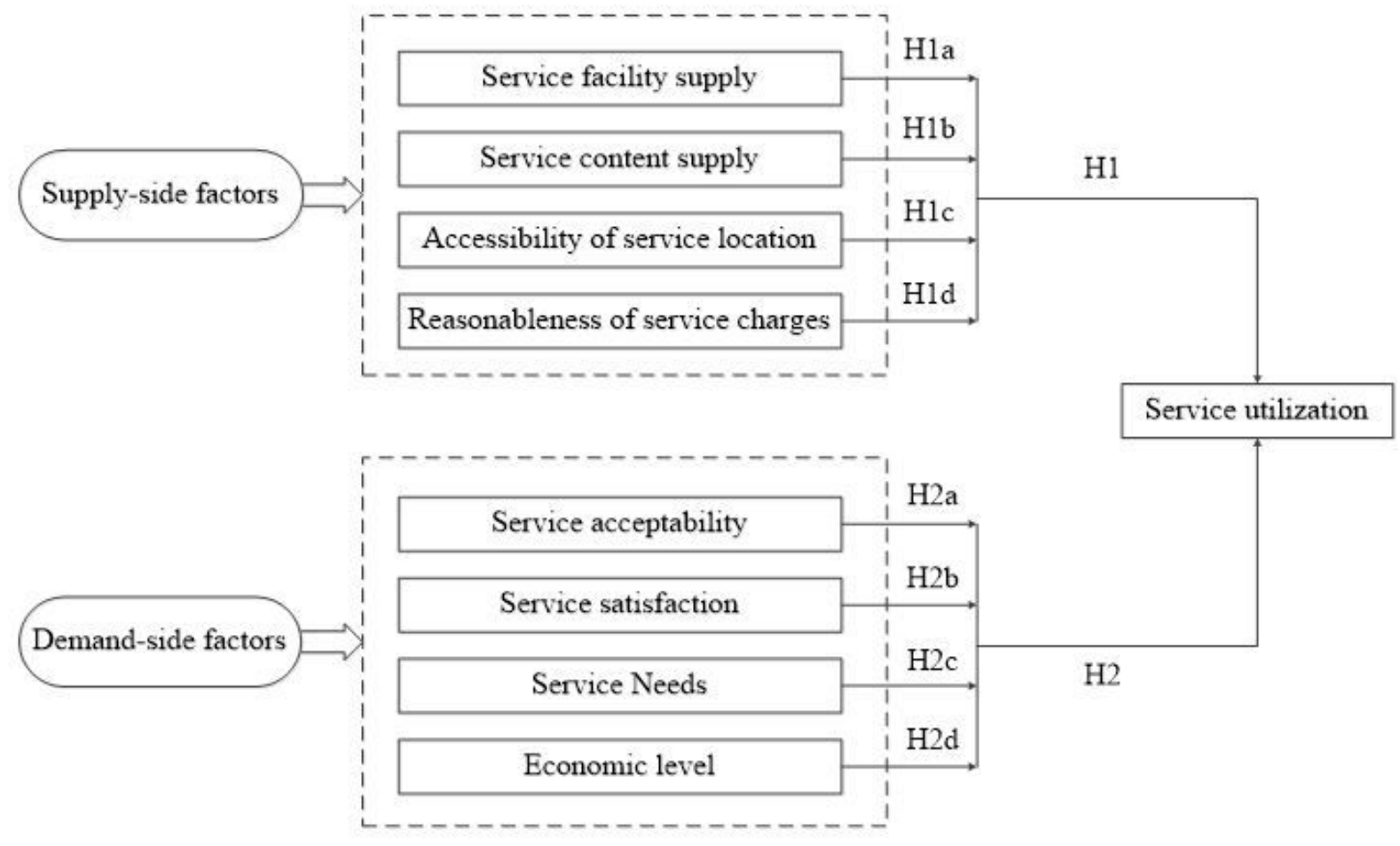

\section{Figure 1}

Analytical framework of community cultural and leisure services utilization 